\title{
Cryogenic-target performance and implosion physics studies on OMEGA ${ }^{\text {a) }}$
}

\author{
V. A. Smalyuk, ${ }^{1, b)}$ R. Betti, ${ }^{1, c)}$ T. R. Boehly, ${ }^{1}$ R. S. Craxton, ${ }^{1}$ J. A. Delettrez, ${ }^{1}$ D. H. Edgell, ${ }^{1}$ \\ V. Yu. Glebov, ${ }^{1}$ V. N. Goncharov, ${ }^{1}$ D. R. Harding, ${ }^{1}$ S. X. Hu, ${ }^{1}$ J. P. Knauer, ${ }^{1}$ \\ F. J. Marshall, ${ }^{1}$ R. L. McCrory, ${ }^{1, c)}$ P. W. McKenty, ${ }^{1}$ D. D. Meyerhofer, ${ }^{1, c)}$ P. B. Radha, ${ }^{1}$ \\ S. P. Regan, ${ }^{1}$ T. C. Sangster, ${ }^{1}$ W. Seka, ${ }^{1}$ R. W. Short, ${ }^{1}$ D. Shvarts, ${ }^{1, d}$ \\ S. Skupsky, ${ }^{1}$ J. M. Soures, ${ }^{1}$ C. Stoeckl, ${ }^{1}$ B. Yaakobi, ${ }^{1}$ J. A. Frenje, ${ }^{2}$ C. K. Li, ${ }^{2}$ \\ R. D. Petrasso, ${ }^{2, e)}$ and F. H. Séguin ${ }^{2}$ \\ ${ }^{1}$ Laboratory for Laser Energetics, University of Rochester, 250 East River Road, Rochester, \\ New York 14623-1299, USA \\ ${ }^{2}$ Plasma Science and Fusion Center, Massachusetts Institute of Technology, Cambridge, \\ Massachusetts 02139, USA
}

(Received 5 December 2008; accepted 12 January 2009; published online 27 February 2009)

\begin{abstract}
Recent progress in direct-drive cryogenic implosions on the OMEGA Laser Facility [T. R. Boehly et al., Opt. Commun. 133, 495 (1997)] is reviewed. Ignition-relevant areal densities of $\sim 200 \mathrm{mg} / \mathrm{cm}^{2}$ in cryogenic $\mathrm{D}_{2}$ implosions with peak laser-drive intensities of $\sim 5$ $\times 10^{14} \mathrm{~W} / \mathrm{cm}^{2}$ were previously reported [T. C. Sangster et al., Phys. Rev. Lett. 100, 185006 (2008)]. The laser intensity is increased to $\sim 10^{15} \mathrm{~W} / \mathrm{cm}^{2}$ to demonstrate ignition-relevant implosion velocities of $3-4 \times 10^{7} \mathrm{~cm} / \mathrm{s}$, providing an understanding of the relevant target physics. Planar-target acceleration experiments show the importance of the nonlocal electron-thermaltransport effects for modeling the laser drive. Nonlocal and hot-electron preheat is observed to stabilize the Rayleigh-Taylor growth at a peak drive intensity of $\sim 10^{15} \mathrm{~W} / \mathrm{cm}^{2}$. The shell preheat caused by hot electrons generated by two-plasmon-decay instability was reduced by using Si-doped ablators. The measured compressibility of planar plastic targets driven with high-compression shaped pulses agrees well with one-dimensional simulations at these intensities. Shock mistiming has contributed to compression degradation of recent cryogenic implosions driven with continuous pulses. Multiple-picket (shock-wave) target designs make it possible for a more robust tuning of the shock-wave arrival times. Cryogenic implosions driven with double-picket pulses demonstrate somewhat improved compression performance at a peak drive intensity of $\sim 10^{15} \mathrm{~W} / \mathrm{cm}^{2}$. (c) 2009 American Institute of Physics. [DOI: 10.1063/1.3078102]
\end{abstract}

\section{INTRODUCTION}

The goal of inertial confinement fusion (ICF) ${ }^{1,2}$ is to implode a spherical target to achieve high compression of the fuel and high temperature of the hot spot to trigger ignition and maximize the thermonuclear energy gain. Both directand indirect-drive concepts of ICF rely on targets with thick cryogenic deuterium-tritium (DT) shells for ignition. ${ }^{1-3}$ While target designs vary in their details, these concepts have common basic physics such as ablator and fuel compressibility, energy coupling and transport, hydrodynamic instabilities, shock tuning, and preheating. Recent OMEGA cryogenic $\mathrm{D}_{2}$ experiments demonstrated ignition-relevant fuel compression with a neutron-averaged areal density of $\sim 200 \mathrm{mg} / \mathrm{cm}^{2}{ }^{4,5}$ This corresponds to an estimated peak fuel density of $\sim 100 \mathrm{~g} / \mathrm{cm}^{3}, \sim 500$ times higher than the initial cryogenic ice density. These experiments were con-

\footnotetext{
${ }^{\mathrm{a})}$ Paper BI1 6, Bull. Am. Phys. Soc. 53, 20 (2008).

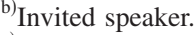

${ }^{c}$ Also at Department of Mechanical Engineering and Department of Physics and Astronomy, University of Rochester.

d) Also at Nuclear Research Center Negev, Israel.

e)Also at Laboratory for Laser Energetics, University of Rochester.
}

ducted at peak drive intensities of $\sim 5 \times 10^{14} \mathrm{~W} / \mathrm{cm}^{2}$ using $10-\mu \mathrm{m}$-thick plastic ablators with an implosion velocity of $\sim 2.4 \times 10^{7} \mathrm{~cm} / \mathrm{s}^{4,5}$ To achieve an ignition-relevant implosion velocity of $\sim 4 \times 10^{7} \mathrm{~cm} / \mathrm{s}$, the peak drive intensity must be increased to $\sim 10^{15} \mathrm{~W} / \mathrm{cm}^{2} \cdot{ }^{3,4}$ Recent direct-drive ICF research on OMEGA focused on understanding the physics of this high-intensity regime. Understanding the dynamics of target implosion is essential to all ignition target designs, whether directly or indirectly driven. This article reviews the results obtained over this past year in the physics of cryogenic-target implosions, including energy coupling and transport, hydrodynamic instabilities, compressibility, shock timing, and preheating.

Section II shows the importance of nonlocal electrons in modeling laser coupling and energy transport. Section III presents recent results from experiments that show stabilization of hydrodynamic instabilities at peak intensities of $\sim 10^{15} \mathrm{~W} / \mathrm{cm}^{2}$. Section IV describes compressibility experiments performed in plastic ablators. Section V describes shock-timing experiments. The compression results from cryogenic $\mathrm{D}_{2}$ spherical implosions are presented in Sec. VI. Section VII describes spherical experiments in Si-doped plastic ablators. Section VIII summarizes these results. 
(a) Peak intensity $\left(\times 10^{15} \mathrm{~W} / \mathrm{cm}^{2}\right)$

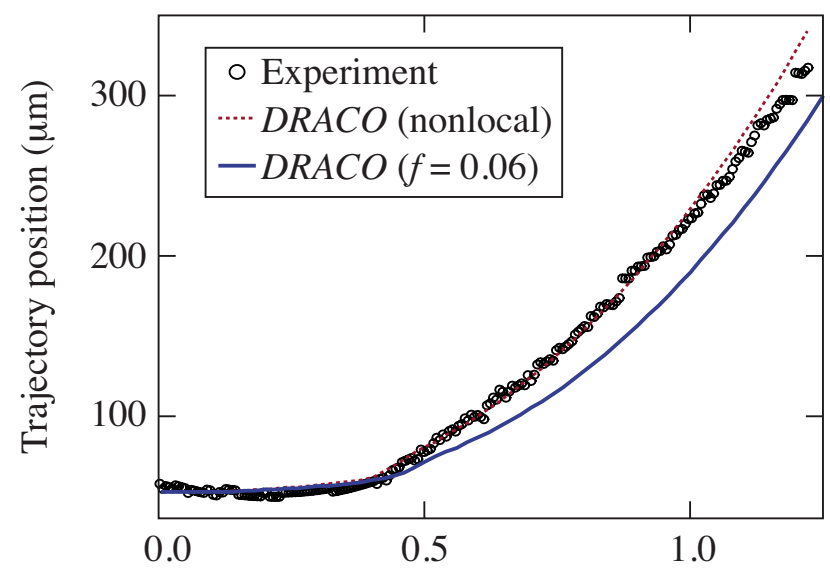

(b)

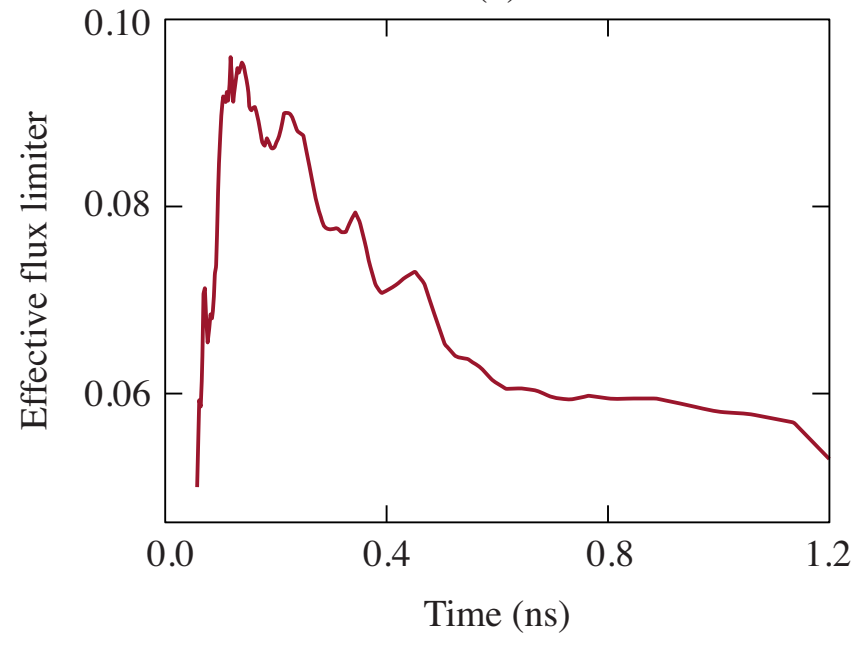

FIG. 1. (Color online) (a) Measured (circles) and simulated target trajectories using flux limiter $f=0.06$ (solid curve) and an effective flux limiter derived from the nonlocal model (dotted curve) shown in (b).

\section{ENERGY COUPLING AND TRANSPORT}

Acceleration experiments with planar plastic foils were conducted to study energy coupling and transport in plastic ablators. ${ }^{6}$ In these experiments, 2.5-mm-diameter, $20-\mu \mathrm{m}$-thick $\mathrm{CH}$ targets were driven with a $1 \mathrm{~ns}$ square pulse shape at a peak laser intensity of $\sim 10^{15} \mathrm{~W} / \mathrm{cm}^{2}$. The targets were driven with 12 overlapped beams using all standard OMEGA beam-smoothing techniques, including distributed phase plates (DPPs), ${ }^{7}$ polarization smoothing (PS) ${ }^{8}$ and smoothing by spectral dispersion (SSD). ${ }^{9}$ The target acceleration was measured using side-on radiography with a streak camera using $\sim 2 \mathrm{keV}$ x rays from a dysprosium sidelighter and compared with two-dimensional (2D) DRACO simulations. ${ }^{6}$ The simulations used a local model for electron transport ${ }^{10}$ with a time-dependent flux limiter derived from a one-dimensional (1D) nonlocal thermal-electron-transport model. ${ }^{11}$ The nonlocal model solves the Boltzmann equation with Krook's collision operator and an appropriate electrondeposition length. It gives an effective time-dependent flux limiter, defined as the ratio of nonlocal heat flux to the freestream heat flux. ${ }^{11}$

The measured target trajectory [Fig. 1(a)] is in good agreement with the simulated trajectory using the effective time-dependent flux limiter shown in Fig. 1(b). Hu et al. ${ }^{6}$ showed that the measured target trajectories are in good agreement with nonlocal model predictions over the broad range of intensities from $\sim 2 \times 10^{14}$ to $1 \times 10^{15} \mathrm{~W} / \mathrm{cm}^{2}$. Predictions using a local model of thermal transport with a constant flux limiter of $f=0.06$ (Ref. 10) (previous standard model for OMEGA experiments) are in good agreement with experiments at intensities below $\sim 5 \times 10^{14} \mathrm{~W} / \mathrm{cm}^{2}$, but break down at peak intensities $\sim 10^{15} \mathrm{~W} / \mathrm{cm}^{2}$, as shown in Fig. 1(a). These results indicate that nonlocal effects are critical for modeling energy coupling and transport in directdrive-ignition designs using high-intensity ultraviolet lasers. Experiments using green and IR lasers have shown that nonlocal effects were important even at much lower intensities of $\sim 1 \times 10^{14} \mathrm{~W} / \mathrm{cm}^{2}{ }^{12,13}$

\section{HYDRODYNAMIC INSTABILITY EXPERIMENTS}

The nonlocal model for electron-thermal transport predicts target decompression at the ablation front ${ }^{11}$ relative to the prediction of the local model. ${ }^{10}$ The decompression at the ablation front is caused by heating from the high-energy tail of the electron distribution. The decompression at the ablation surface reduces the growth rate of the Rayleigh-Taylor (RT) instability. ${ }^{12-15}$ In the linear stage of the RT instability, the growth rate as a function of modulation wave number $k$ in plastic targets is given by the dispersion relation, ${ }^{16}$

$$
\gamma(k)=0.94\left[\mathrm{~kg} /\left(1+k L_{n}\right)\right]^{0.5}-1.5 k V_{a},
$$

where $g$ is the target acceleration, $V_{a}$ is the ablation velocity, and $L_{n}$ is the density scale length. The growth rate is proportional to the first acceleration term and is reduced by the second stabilizing term $-1.5 k V_{a}$, caused by material ablation. When the target is decompressed, the ablation velocity increases, resulting in a reduced RT growth rate. This reduction is stronger for modulations with high wave numbers (shorter wavelengths). This was experimentally observed in $20-\mu \mathrm{m}$-thick planar $\mathrm{CH}$ targets driven with various square drive pulses. ${ }^{14,15}$

In this work, 20- $\mu$ m-thick $\mathrm{CH}$ targets were driven with 12 overlapped beams with full beam smoothing including DPPs, ${ }^{7}$ PS, ${ }^{8}$ and SSD. ${ }^{9}$ The RT growth of preimposed 2D modulations was measured with through-foil, $\mathrm{x}$-ray radiography ${ }^{14,15}$ using $\sim 1.3 \mathrm{keV} \times$ rays from a uranium backlighter. In the RT experiments, the $2 \mathrm{D}$ preimposed modulations had wavelengths of 20,30 , and $60 \mu \mathrm{m}$ with initial amplitudes of $0.05,0.05$, and $0.125 \mu \mathrm{m}$, respectively. Results of RT growth experiments are shown in Fig. 2 for a $1 \mathrm{~ns}$ drive at an intensity of $\sim 1 \times 10^{15} \mathrm{~W} / \mathrm{cm}^{2}$ [Figs. 2(a) $-2(\mathrm{c})]$ and a $1.6 \mathrm{~ns}$ drive at an intensity of $\sim 5$ $\times 10^{14} \mathrm{~W} / \mathrm{cm}^{2}$ [Figs. 2(d)-2(f)]. The experimental data at a $60 \mu \mathrm{m}$ wavelength are weakly affected by the stabilizing term $-1.5 k V_{a}$ [Figs. 2(a) and 2(d)]. This modulation grows more rapidly at a drive intensity of $\sim 10^{15} \mathrm{~W} / \mathrm{cm}^{2}$ than at $\sim 5 \times 10^{14} \mathrm{~W} / \mathrm{cm}^{2}$. This indicates that the acceleration is higher at high intensity, as expected. At an intensity of $\sim 5$ $\times 10^{14} \mathrm{~W} / \mathrm{cm}^{2}$ the short-wavelength modulations (at wavelengths of 20 and $30 \mu \mathrm{m}$ ) grow faster than the long, $60 \mu \mathrm{m}$ 

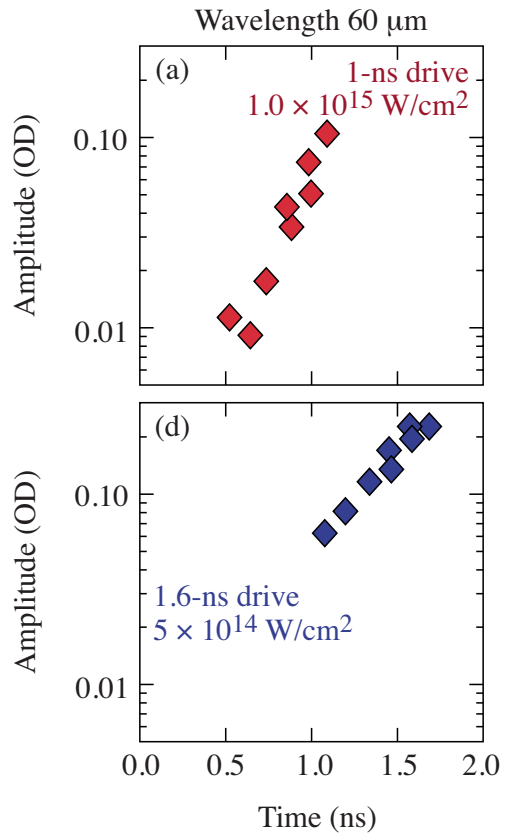
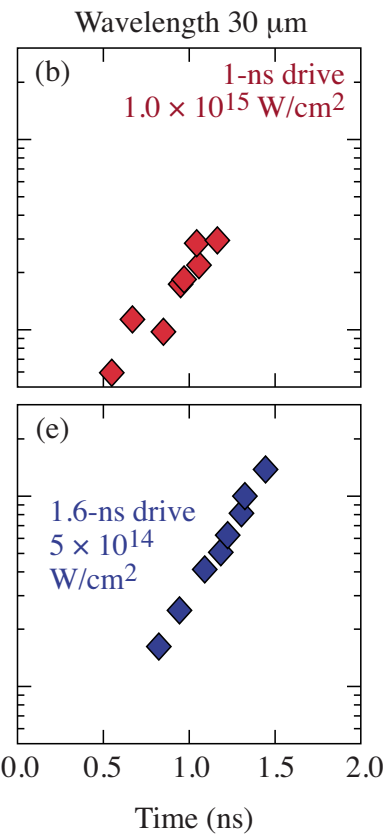
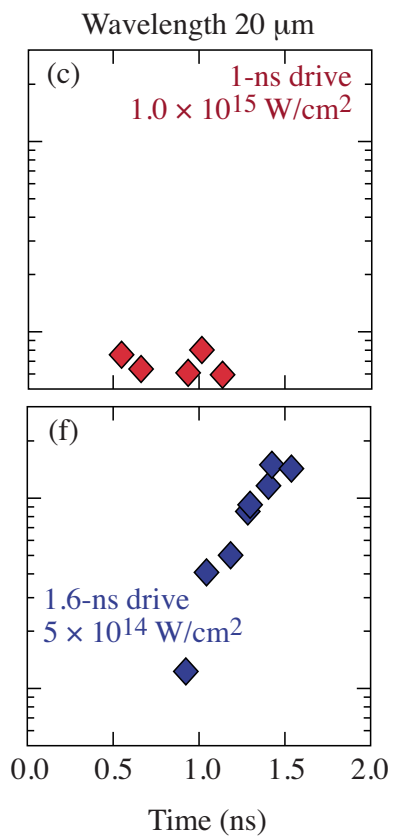

FIG. 2. (Color online) Optical-depth modulations vs time for a $1 \mathrm{~ns}$ square laser drive at an intensity of $\sim 1 \times 10^{15} \mathrm{~W} / \mathrm{cm}^{2}[(\mathrm{a})-(\mathrm{c})]$ and with a $1.6 \mathrm{~ns}$ square laser drive at an intensity of $\sim 5 \times 10^{14} \mathrm{~W} / \mathrm{cm}^{2}[(\mathrm{~d})-(\mathrm{f})]$ with wavelengths of 60,30 , and $20 \mu \mathrm{m}$.

wavelength modulation. At a high intensity of 1 $\times 10^{15} \mathrm{~W} / \mathrm{cm}^{2}$, this trend is reversed: $60 \mu \mathrm{m}$ wavelength modulation grows faster than the $30 \mu \mathrm{m}$ perturbation, with the $20 \mu \mathrm{m}$ wavelength perturbation completely stabilized.

This stabilization is consistent with the increased ablation velocity and density scale length at high intensity predicted by the nonlocal electron transport model. ${ }^{11,14} 2 \mathrm{D}$ simulations, based on time-dependent local flux limiter, were compared with the experimental data and presented in Ref. 14. At laser intensity of $\sim 5 \times 10^{14} \mathrm{~W} / \mathrm{cm}^{2}$ (not affected by nonlocal preheat), the measured RT growth agrees well with 2D simulations based on a local model of thermal-electron transport. The RT growth at drive intensities above $\sim 1.0$ $\times 10^{15} \mathrm{~W} / \mathrm{cm}^{2}$ (where nonlocal preheat becomes important) was strongly stabilized compared to the local model predictions. The stabilization is also correlated with the hotelectron signal from two-plasmon-decay (TPD) instability. ${ }^{14,17,18}$ This signal becomes detectable at intensities above $\sim 5 \times 10^{14} \mathrm{~W} / \mathrm{cm}^{2}$, similar to previous experiments. ${ }^{4,19}$ The relationship between the x-ray emission and the target preheat is still under investigation. The strong measured RT growth stabilization reduces the requirements for mitigation of the hydroinstability growth in direct-driveignition capsules on the National Ignition Facility (NIF). ${ }^{14}$ Future experiments will distinguish between nonlocal and hot-electron contributions to the ablation-surface preheating and will study the effects of hot electrons on target acceleration.

\section{PLASTIC-ABLATOR COMPRESSIBILITY}

Figure 3 shows a schematic of the plastic-ablator compressibility experiments ${ }^{20}$ performed with $\sim 125$ - $\mu$ m-thick, $\sim 280$ - $\mu \mathrm{m}$-wide plastic planar targets driven with a highcompression, 3-ns-long shaped pulse at a peak drive intensity of $\sim 1 \times 10^{15} \mathrm{~W} / \mathrm{cm}^{2}$, as shown in Fig. 4(a). The targets were driven with 14 overlapped beams with full beam smoothing including DPP's, ${ }^{7}$ PS, ${ }^{8}$ and SSD. ${ }^{9}$ The target compression was measured with $\mathrm{x}$-ray side-on radiography using an $\sim 6.4-\mathrm{keV}$ iron sidelighter. The 2-ns-long foot of the pulse sends a shock wave that compresses the ablator by approximately three times. The compression increases up to approximately nine times when the main shaped pulse sends a compression wave through the target. Figures 4(b) and 4(c) compare the measured and simulated optical-depth compression of the target. The shock and compression waves travel from right to left in these data. The predictions for (b) $2.5 \mathrm{~ns}$ and (c) 2.9 ns show good agreement with experiment, confirming the compression of the plastic ablator by a shaped laser drive. In Fig. 4(b) at $2.5 \mathrm{~ns}$, the left part at optical depth

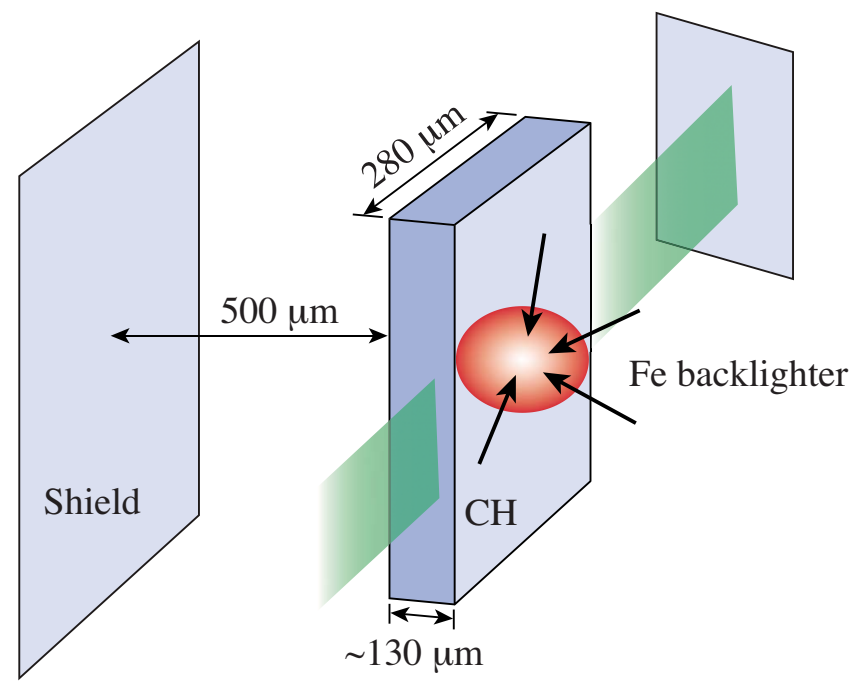

FIG. 3. (Color online) Experimental setup for plastic-ablator compressibility experiments performed with $\sim 125$ - $\mu \mathrm{m}$-thick, $\sim 280$ - $\mu \mathrm{m}$-wide plastic planar targets driven with 14 overlapped beams. The target compression was measured with $\mathrm{x}$-ray side-on radiography using an $\sim 6.4 \mathrm{keV}$ iron sidelighter. 


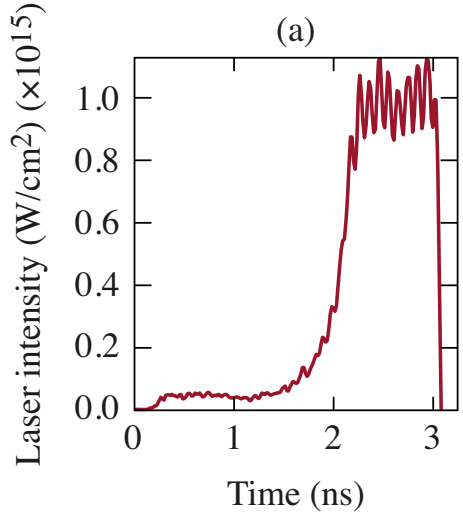

(b)

(c)

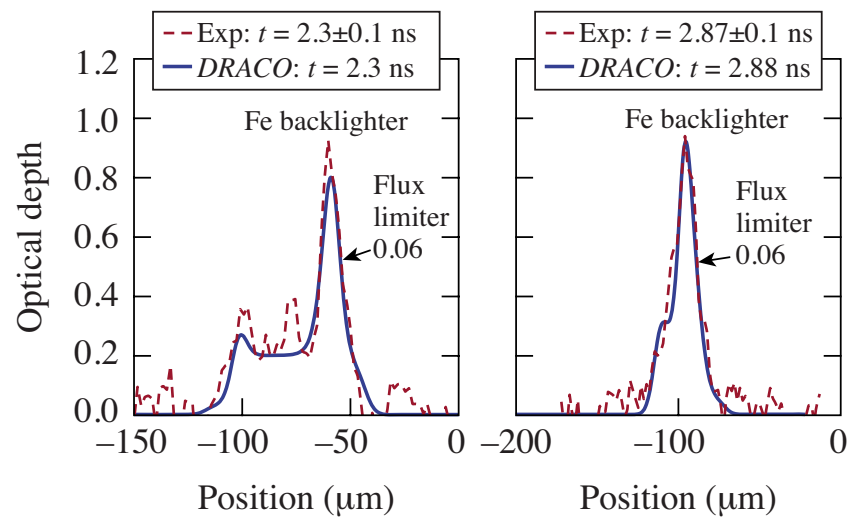

FIG. 4. (Color online) (a) High-compression, 3-ns long laser-pulse shape. The measured (dashed curves) and simulated (solid curves) optical-depth target compression at (b) $2.5 \mathrm{~ns}$ and (c) $2.9 \mathrm{~ns}$. The shock waves travel from right to left. The predictions show good agreement with measurements.

of $\sim 0.2$ represents the uncompressed part of the target, while the right part at optical depth of $\sim 0.8$ represents the compressed (by shock and compression waves) part of the target. Reference 20 presents more detailed comparison of the experimental data with simulations. These measurements validated the hydrodynamics and equation-of-state (SESAME) of the shock and compression wave predicted by the 2D hydrocode DRACO (Ref. 20) used to simulate the experiments. Similar experiments conducted at lower intensities of $\sim 5 \times 10^{14} \mathrm{~W} / \mathrm{cm}^{2}$ also showed agreement with hydrosimulations, while experiments at an intensity of $\sim 1.5$ $\times 10^{15} \mathrm{~W} / \mathrm{cm}^{2}$ (higher than required for ignition on the NIF) showed target decompression that was correlated with the presence of hot electrons generated by TPD instability. ${ }^{20} \mathrm{At}$ intensity of $\sim 1.0 \times 10^{15} \mathrm{~W} / \mathrm{cm}^{2}$, the compression of the bulk of the target was not significantly affected by hotelectron preheat, while the hot electrons may have some contribution to the stabilization of the RT growth at the ablation surface, discussed in Sec. III. Additional experiments are needed to address these issues in more detail.

\section{SHOCK TIMING}

Figure 5 shows a schematic of the shock-timing experiments performed with spherical $10-\mu \mathrm{m}$-thick CD shells filled with cryogenic $\mathrm{D}_{2}$ liquid. ${ }^{21}$ The target cone makes it possible for the active shock breakout (ASBO) (Ref. 22) system to

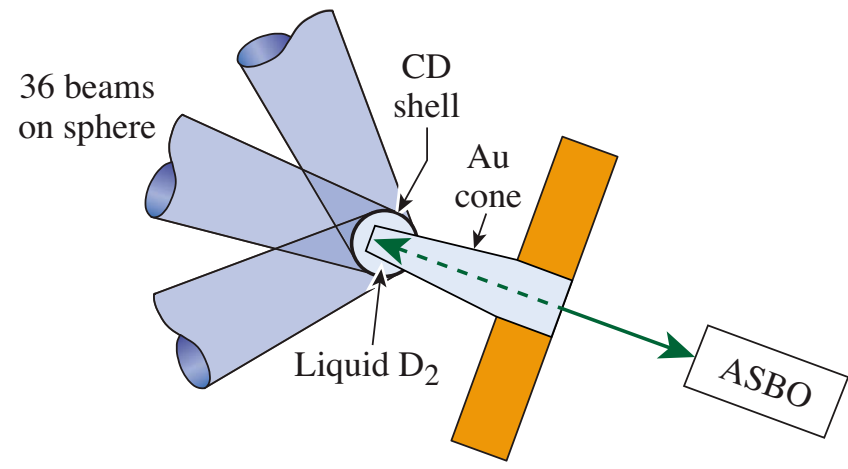

FIG. 5. (Color online) Schematic of shock-timing experiments consisting of spherical 10- $\mu \mathrm{m}$-thick CD shells filled with liquid deuterium driven with 36 overlapped OMEGA beams. The targets have openings for ASBO diagnostics to probe shocks in liquid deuterium.

probe the shock waves in liquid deuterium. The experiments were performed with 36 overlapped OMEGA beams using all standard OMEGA beam-smoothing techniques, including DPPs, ${ }^{7}$ PS, ${ }^{8}$ and SSD. ${ }^{9}$ The diagnostics probed the central region of the target, which had the same illumination conditions as cryogenic spherical implosions. Figure 6(a) shows
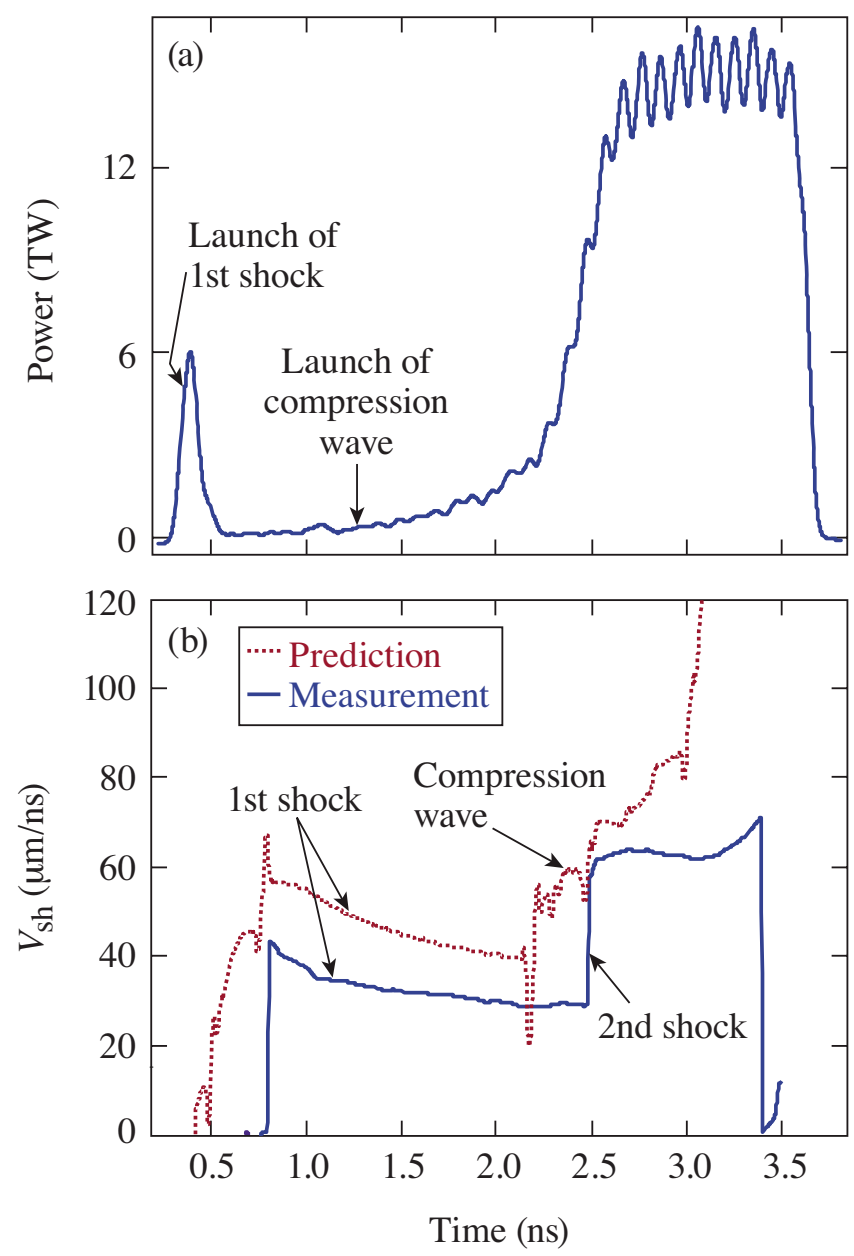

FIG. 6. (Color online) (a) The laser-pulse shape for the continuous laserpulse experiments with peak on-target intensity of $\sim 7 \times 10^{14} \mathrm{~W} / \mathrm{cm}^{2}$. (b) The measured (solid curve) and simulated (dotted curve) shock velocities as a function of time. 

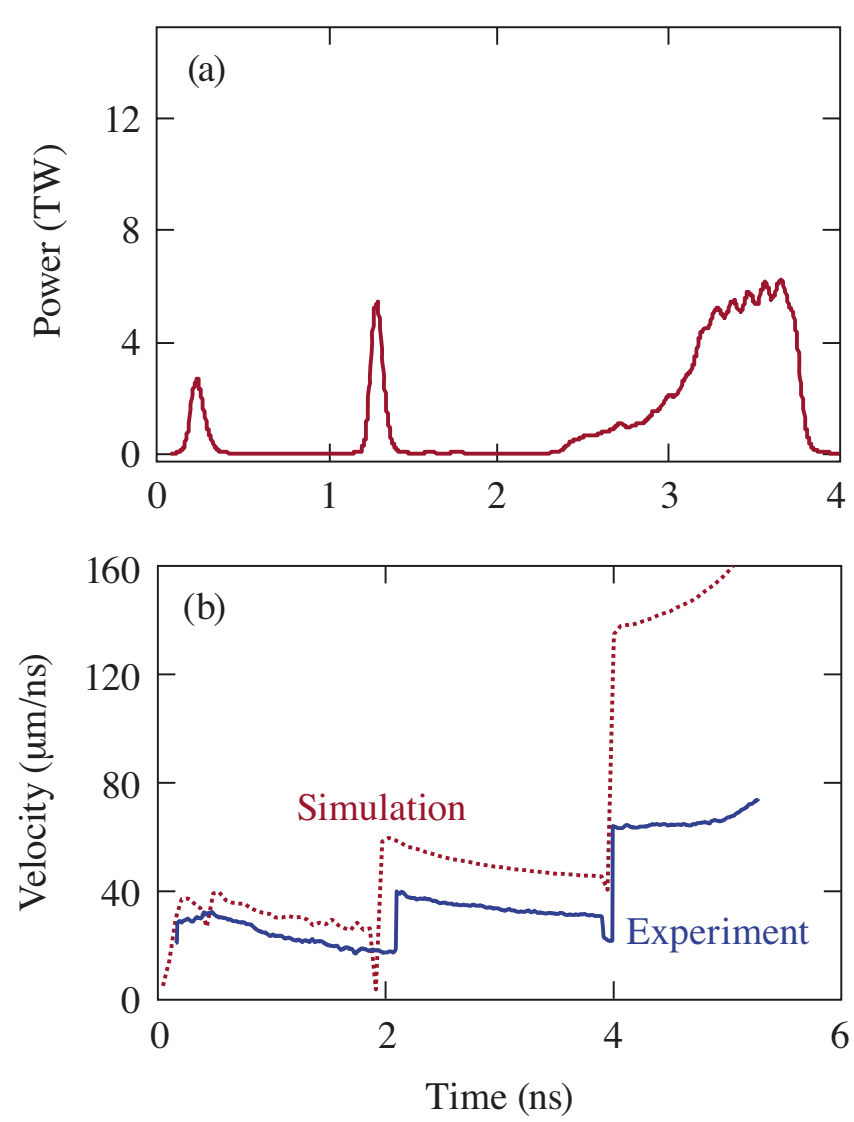

FIG. 7. (Color online) (a) The pulse shape for the double-picket, laser-pulse experiments with peak on-target intensity of $\sim 3 \times 10^{14} \mathrm{~W} / \mathrm{cm}^{2}$. (b) The measured (solid curve) and simulated (dotted curve) shock velocities as a function of time.

the pulse shape used during one of the experiments. The measured shock velocity as a function of time (solid curve) is shown in Fig. 6(b). The data are compared with the 1D prediction, shown by the dotted curve. In the $1 \mathrm{D}$ prediction, the picket sends the first shock that decays as it travels through the target. This is shown by the decreasing shock velocity as a function of time. As a compression wave is launched by the shaped laser pulse starting at $\sim 1.2 \mathrm{~ns}$, the shock velocity gradually increases in the simulation. The measurements indicate that the compression wave turns into the shock wave inside the target. The measured shock velocity from the first shock is smaller than predicted. This measurement suggests that energy coupling from the picket and low-intensity part of the pulse is reduced, compared to the simulation. The adiabat (the ratio of the plasma pressure to the Fermi pressure of a fully degenerate electron gas) of the $\mathrm{CD}$ shell and $\mathrm{D}_{2}$ fuel is likely higher than simulated, leading to compression degradation in spherical implosions.

Since 1D simulations incorrectly predict the shock timing, experimental measurements can be used to tune multiple hydrodynamic waves. Experimentally, it is easier to tune shock waves than compression waves because the multiple shock waves are much easier to create and interpret. Figure 7(a) shows the double-picket pulse shape used for one such experiment and the measured shock velocity as a function of time [blue curve in Fig. 7(b)]. The data are compared with $1 \mathrm{D}$ prediction shown by the red curve. In the $1 \mathrm{D}$ prediction, the first picket sends the first shock wave that decays as it travels through the target. The second picket sends a stronger second shock that travels faster and overtakes the first shock wave at $\sim 2 \mathrm{~ns}$. The main part of the pulse sends a third shock wave, which coalesces with the two earlier shocks at $\sim 4$ ns. The experiment shows that the shocks coalesce. However, the shock velocities are smaller in the experiment than in the simulation.

In order to set the correct predicted adiabat at the innershell surface, the shock velocities and coalescence times of the shocks have to be the same as in the simulations. All shocks have to coalesce at the inner surface of the ice. When properly tuned in strength and timing, the shocks minimize the adiabat of the fuel. If the later, stronger shocks overtake the first shock too early, a large portion of the fuel is heated by this strong shock and will be on higher adiabat and harder to compress. Late coalescence means that previous shocks have time to unload significant amount of material from the inner surface of the ice, creating a low-density blowoff that would be significantly heated by the subsequent shocks, again placing a fuel on high adiabat. In both continuous and double-picket experiments, the shock velocities are different from those simulated indicating and as a result, the fuel adiabats are different from the simulated. Since 1D simulations do not predict shock strengths correctly, the shocks were tuned experimentally by measuring target-compression performance in spherical implosion, presented in Sec. VI. In these experiments, all shocks were launched before the hot electrons generated; therefore the hot electrons had no effect on the shock dynamics. Future experiments will tune shock waves using triple-picket pulses with the square main pulse. This technique is similar to that used for shock tuning in indirect-drive-ignition designs. $1,2,21$

\section{CRYOGENIC-TARGET COMPRESSION}

Figure 8 shows compression results obtained in spherical implosions with outer $10-\mu \mathrm{m}$-thick CD ablators and inner 95- $\mu \mathrm{m}$-thick cryogenic- $\mathrm{D}_{2}$-ice fuel shells. Figure 8(a) shows three examples of continuous laser pulses at a peak intensity range from $\sim 5 \times 10^{14}$ to $\sim 8 \times 10^{14} \mathrm{~W} / \mathrm{cm}^{2}$. Figure $8(\mathrm{~b})$ shows an example of a double-picket pulse at a peak intensity range of $\sim 9 \times 10^{14} \mathrm{~W} / \mathrm{cm}^{2}$. Figure $8(\mathrm{c})$ shows a comparison of the compression results obtained with these two types of laser pulses. The neutron-averaged areal density was predicted to be $\sim 250 \mathrm{mg} / \mathrm{cm}^{2}$ with adiabat of $\alpha \sim 2$ for all implosions, assuming that the shock pulses were properly tuned. The highest compression with measured areal density in the range of $180-200 \mathrm{mg} / \mathrm{cm}^{2}$ was obtained at the peak intensity of $\sim 5 \times 10^{14} \mathrm{~W} / \mathrm{cm}^{2}$. Two of the four data points at this intensity were presented in Ref. 5, while the other two were obtained recently, showing a good repeatability of these results. The neutron yield varied by a factor of $\sim 5$ due to variations in the inner ice roughness and the target offset from a target chamber center in these implosions. While the yield varied, the areal density did not, showing that the areal density is a robust measure of target compression, as previously shown in plastic implosions. ${ }^{23}$

By increasing the peak intensity in the continuous-pulse 

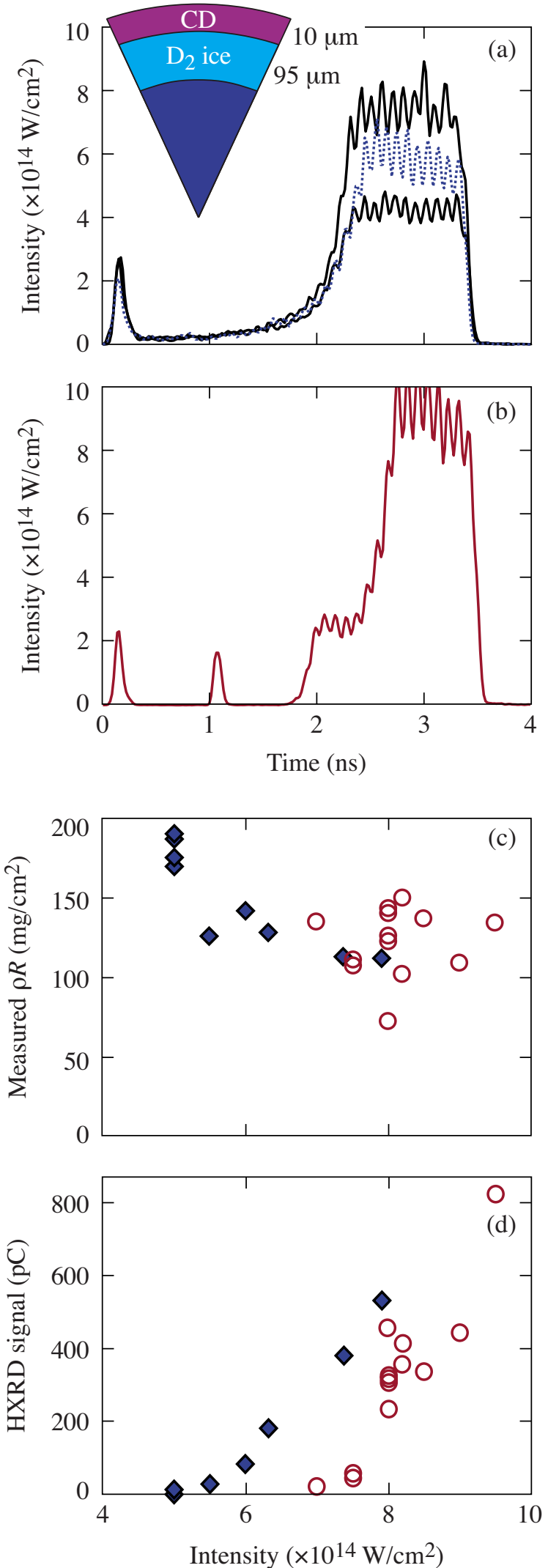

FIG. 8. (Color online) (a) Schematic of spherical targets used in implosions consisting of outer $10-\mu \mathrm{m}$-thick $\mathrm{CD}$ and inner cryogenic $\mathrm{D}_{2}$ ice shells driven with continuous laser pulses at peak intensities ranging from $\sim 5$ $\times 10^{14} \mathrm{~W} / \mathrm{cm}^{2}$ to $\sim 8 \times 10^{14} \mathrm{~W} / \mathrm{cm}^{2}$. (b) An example of a double-picket laser pulse with a peak intensity of $\sim 9 \times 10^{14} \mathrm{~W} / \mathrm{cm}^{2}$. (c) Measured neutron-averaged areal density as a function of peak drive intensity with continuous (diamonds) and double-picket (circles) pulses. (d) Hard x-ray signal as a function of peak drive intensity with continuous (diamonds) and double-picket (circles) pulses. implosions, the areal density did not increase, shown by blue diamonds [Fig. 8(c)]. As discussed in Sec. V, the shocks were not properly timed in these implosions, resulting in a decrease in the measured compression. The presumably bettertimed, double-picket implosions produced somewhat higher compression with areal densities up to $\sim 150 \mathrm{mg} / \mathrm{cm}^{2}$ at high peak intensities, shown by red open circles [Fig. 8(c)]. The variations in these data are due to variations in the picket energies and uncertainties for the shock-timing experiments. These multiple-picket designs are being optimized in current campaigns. While agreement between theory and experiment was good for shaped pulses with no pickets, as shown in Sec. IV and Fig. 4, the agreement is not good for shaped pulses with pickets. As discussed in Refs. 4 and 11, the measured laser absorption does not agree with the simulated absorption in the pickets, possibly causing the shock mistuning. Figure 8(d) presents the measured hard x-ray signal, produced by hot electrons from TPD instability, as a function of peak intensity for both types of drive pulses. The hard x-ray signal increases with peak intensity. ${ }^{24}$ The preheat energy estimated based on the measured hard x-ray signal is of the order of $\sim 20 \mathrm{~J}$ in the high-intensity implosions. ${ }^{4}$ This corresponds to $\sim 0.1 \%$ of the total laser energy. ${ }^{4}$ With such levels of the preheat, the areal density is expected to be reduced from $\sim 250$ to $\sim 210 \mathrm{mg} / \mathrm{cm}^{2}$ if the shock timing is optimized. These levels of preheat should not preclude obtaining an ignition-relevant areal density of $\sim 200 \mathrm{mg} / \mathrm{cm}^{2}$ at peak intensities of $\sim 1 \times 10^{15} \mathrm{~W} / \mathrm{cm}^{2}$. The fact that the measured compression is below this level suggests that shock timing still must be improved and/or the hot-electron preheat is larger than previously estimated.

As discussed above, the two main contributions to the compression performance degradation of the implosions with both continuous and double-picket pulse shapes are the shock mistiming and hot-electron preheat. At the low intensities of $\sim 5 \times 10^{14} \mathrm{~W} / \mathrm{cm}^{2}$ and low hot-electron signal, the double-picket implosion perform worse that the continuouspulse implosions. This indicates that the shock mistiming is the degradation factor impacting all types of implosions. This has been also shown in Sec. V, where both continuous and double-picket pulses showed disagreement of the shock strength with simulations. As intensity increases to $\sim 1$ $\times 10^{15} \mathrm{~W} / \mathrm{cm}^{2}$ and hot-electron signal increases, both continuous and double-picket implosions show degradation from the areal density of $\sim 200 \mathrm{mg} / \mathrm{cm}^{2}$ achieved at peak intensities of $\sim 5 \times 10^{14} \mathrm{~W} / \mathrm{cm}^{2}$. Both shock mistiming and hotelectron preheat contribute to this degradation. Yet, at this point, it is difficult to determine precisely the magnitude of the contribution of these two factors to observed degradation. This is because the hot-electron preheat can only be roughly estimated from the measured hot-electron signals (as discussed in previous paragraph) and the adiabat at the inner-ice surface cannot be precisely determined from the shock strength data discussed in Sec. V. As a result, both shock mistiming and hot-electron preheat continue to be of high concern in direct-drive ICF. The future experiments with triple-picket pulse shapes and high- $Z$ ablators will address these most important issues in the direct-drive program. 


\section{PREHEAT}

An important source of compression degradation is the shell preheat caused by hot electrons generated by TPD instability. ${ }^{4,18,19,24}$ This preheat was shown to be virulent in DT and $\mathrm{D}_{2}$ ablators ${ }^{4,24}$ and was reduced by using plastic ablators. ${ }^{4,5}$ As a result, the highest ignition-relevant areal densities with shell $\rho R$ of $\sim 200 \mathrm{mg} / \mathrm{cm}^{2}$ were achieved in cryogenic $\mathrm{D}_{2}$-fuel implosions with plastic ablators when the hot-electron preheat was reduced to zero at a moderate laserdrive peak intensity of $\sim 5 \times 10^{14} \mathrm{~W} / \mathrm{cm}^{2}{ }^{5}$ By increasing the peak intensity to $\sim 1 \times 10^{15} \mathrm{~W} / \mathrm{cm}^{2}$, the implosion velocity can be raised to levels required for ignition, but hard $\mathrm{x}$-ray signals, associated with TPD hot electrons also increase, ${ }^{24}$ as shown in Fig. 8(d). While current hot-electron preheat estimates in plastic-ablator OMEGA implosions (with the estimated cold-shell preheat-energy fraction approaching $\sim 0.1 \%$ of the total laser energy) do not preclude achieving ignition-relevant compression (with shell $\rho R$ of $\sim 200 \mathrm{mg} / \mathrm{cm}^{2}$ ) at high peak intensities of $\sim 1$ $\times 10^{15} \mathrm{~W} / \mathrm{cm}^{2}$ and an initial shell adiabat of $\alpha \sim 2$ (Ref. 4), the longer plasma scale lengths in NIF targets make them potentially more vulnerable to hot-electron production than OMEGA targets. ${ }^{24}$ While there are no reliable predictive capabilities for hot-electron preheat due to the very complex nature of nonlinear TPD instability, higher- $Z$ ablators are expected to mitigate the hot-electron preheat compared to the plastic ablators. Plastic ablators with $5 \%$ by atom of Si dopant were used recently ${ }^{25}$ for this purpose.

Figure 9 shows a comparison of the hard x-ray signals measured in plastic and Si-doped plastic implosions. The implosions were performed with shaped pulses in which the peak intensity varied from $\sim 0.8$ to $\sim 1.1 \times 10^{15} \mathrm{~W} / \mathrm{cm}^{2}$ and a drive energy from $\sim 18$ to $\sim 27 \mathrm{~kJ}$. Two representative pulse shapes are shown in Fig. 9(a). The plastic and Si-doped plastic shells were $27 \mu \mathrm{m}$ thick and a concentration of $\mathrm{Si}$ dopant in plastic shells was 5\% by atom. The comparison of the measured hard $\mathrm{x}$-ray signals in the $>40 \mathrm{keV}$ channel [Fig. 9(b)] shows that the signals grow exponentially with the drive energy in $\mathrm{CH}$ implosions as drive energy increases. The signals were reduced in Si-doped CH shells at low drive energies; the reduction was $\sim 1.5$ times at higher drive energies and peak intensities of $\sim 1.1 \times 10^{15} \mathrm{~W} / \mathrm{cm}^{2}$. Future experiments will use higher- $Z$ ablators to further reduce hotelectron preheat.

\section{CONCLUSIONS}

Progress in cryogenic-implosion physics on OMEGA was reviewed in this article. After achieving ignition-relevant areal densities of $\sim 200 \mathrm{mg} / \mathrm{cm}^{2}$ in cryogenic $\mathrm{D}_{2}$ implosions at peak laser-drive intensities of $\sim 5 \times 10^{14} \mathrm{~W} / \mathrm{cm}^{2}$, the focus of the program has been on understanding the compression physics at a peak laser-drive intensities of $\sim 1$ $\times 10^{15} \mathrm{~W} / \mathrm{cm}^{2}$ that are required to achieve ignition-relevant implosion velocities. Acceleration experiments showed the importance of the nonlocal electron-thermal-transport effects in modeling the laser drive. The nonlocal and hot-electron preheat was shown to stabilize RT growth at a peak drive intensity of $\sim 1 \times 10^{15} \mathrm{~W} / \mathrm{cm}^{2}$. The measured compressibil-
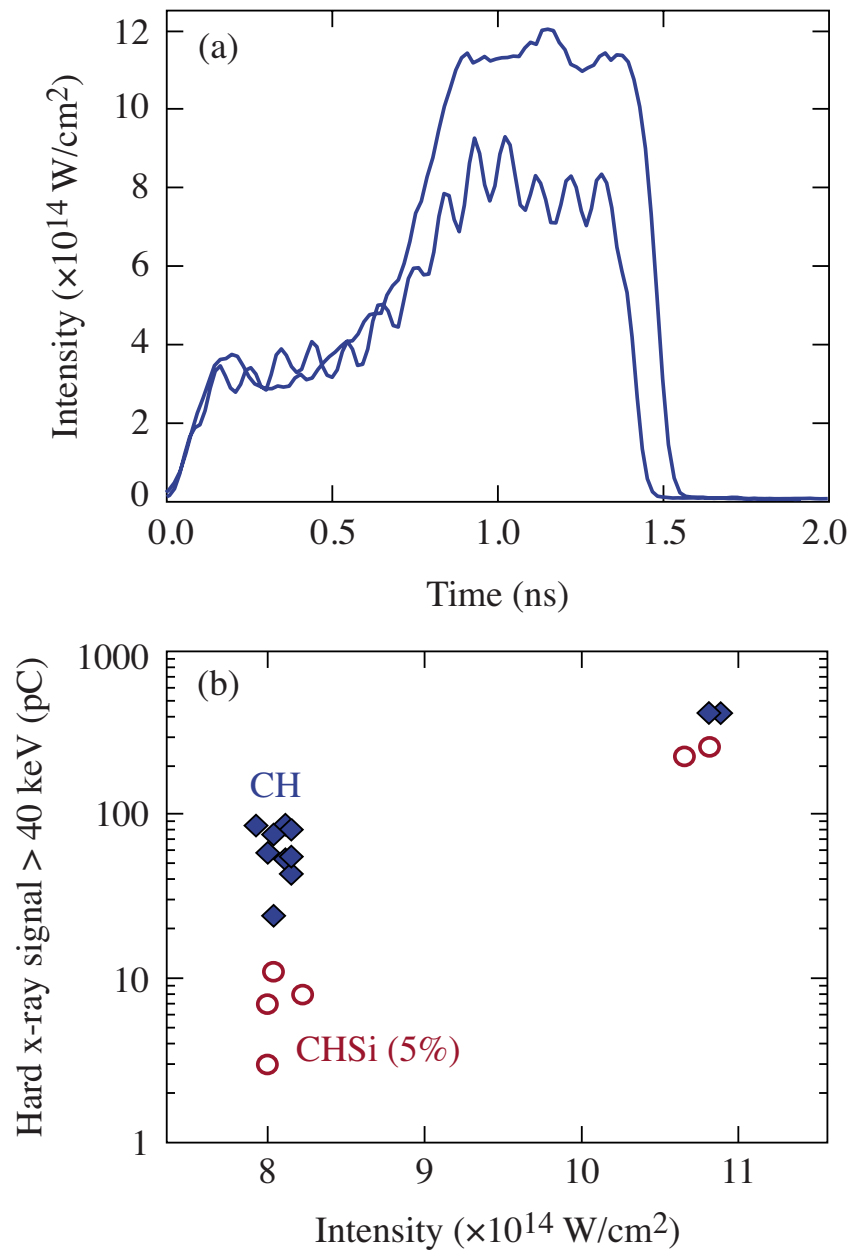

FIG. 9. (Color online) (a) Two representative pulse shapes used to implode $27-\mu \mathrm{m}$-thick plastic and Si-doped (5\% by atom) plastic shells. (b) Hard $\mathrm{x}$-ray signals measured in plastic (diamonds) and Si-doped (circles) implosions.

ity of plastic targets driven with high-compression, shaped pulses agrees well with 1D predictions. Shock mistiming has been shown to be an important mechanism in compression degradation of recent cryogenic implosions driven with continuous pulses. Cryogenic implosions driven with doublepicket pulses, which are easier to tune than continuous pulses, demonstrate some improvement in compression performance at a peak drive intensity of $\sim 1 \times 10^{15} \mathrm{~W} / \mathrm{cm}^{2}$. The shell preheat caused by hot electrons generated by TPD instability was reduced by using Si-doped ablators. Future experiments will investigate higher- $Z$ ablators (such as glass or $\mathrm{Si})$ for further hot-electron preheat reduction. Some progress in understanding ignition-relevant cryogenic-target implosions has been made on OMEGA since the publication of Ref. 4.

\section{ACKNOWLEDGMENTS}

This work was supported by the U.S. Department of Energy Office of Inertial Confinement Fusion under Cooperative Agreement No. DE-FC52-08NA28302, the University of Rochester, and the New York State Energy Research and Development Authority. 
${ }^{1}$ S. Atzeni and J. Meyer-ter-Vehn, The Physics of Inertial Fusion: Beam Plasma Interaction, Hydrodynamics, Hot Dense Matter, International Series of Monographs on Physics (Clarendon, Oxford, 2004).

${ }^{2}$ J. D. Lindl, Inertial Confinement Fusion: The Quest for Ignition and Energy Gain Using Indirect Drive (Springer-Verlag, New York, 1998).

${ }^{3}$ S. E. Bodner, D. G. Colombant, A. J. Schmitt, and M. Klapisch, Phys. Plasmas 7, 2298 (2000).

${ }^{4}$ R. L. McCrory, D. D. Meyerhofer, R. Betti, R. S. Craxton, J. A. Delettrez, D. H. Edgell, V. Yu Glebov, V. N. Goncharov, D. R. Harding, D. W. Jacobs-Perkins, J. P. Knauer, F. J. Marshall, P. W. McKenty, P. B. Radha, S. P. Regan, T. C. Sangster, W. Seka, R. W. Short, S. Skupsky, V. A. Smalyuk, J. M. Soures, C. Stoeckl, B. Yaakobi, D. Shvarts, J. A. Frenje, C. K. Li, R. D. Petrasso, and F. H. Séguin, Phys. Plasmas 15, 055503 (2008). ${ }^{5}$ T. C. Sangster, V. N. Goncharov, P. B. Radha, V. A. Smalyuk, R. Betti, R. S. Craxton, J. A. Delettrez, D. H. Edgell, V. Yu. Glebov, D. R. Harding, D. Jacobs-Perkins, J. P. Knauer, F. J. Marshall, R. L. McCrory, P. W. McKenty, D. D. Meyerhofer, S. P. Regan, W. Seka, R. W. Short, S. Skupsky, J. M. Soures, C. Stoeckl, B. Yaakobi, D. Shvarts, J. A. Frenje, C. K. Li, R. D. Petrasso, and F. H. Séguin, Phys. Rev. Lett. 100, 185006 (2008).

${ }^{6}$ S. X. Hu, V. Smalyuk, V. N. Goncharov, D. Shvarts, T. C. Sangster, D. D. Meyerhofer, and S. Skupsky, Phys. Rev. Lett. 101, 055002 (2008).

${ }^{7}$ Y. Lin, T. J. Kessler, and G. N. Lawrence, Opt. Lett. 20, 764 (1995).

${ }^{8}$ T. R. Boehly, V. A. Smalyuk, D. D. Meyerhofer, J. P. Knauer, D. K. Bradley, R. S. Craxton, M. J. Guardalben, S. Skupsky, and T. J. Kessler, J. Appl. Phys. 85, 3444 (1999).

${ }^{9}$ S. P. Regan, J. A. Marozas, J. H. Kelly, T. R. Boehly, W. R. Donaldson, P. A. Jaanimagi, R. L. Keck, T. J. Kessler, D. D. Meyerhofer, W. Seka, S. Skupsky, and V. A. Smalyuk, J. Opt. Soc. Am. B 17, 1483 (2000).

${ }^{10}$ R. C. Malone, R. L. McCrory, and R. L. Morse, Phys. Rev. Lett. 34, 721 (1975).

${ }^{11}$ V. N. Goncharov, O. V. Gotchev, E. Vianello, T. R. Boehly, J. P. Knauer, P. W. McKenty, P. B. Radha, S. P. Regan, T. C. Sangster, S. Skupsky, V. A. Smalyuk, R. Betti, R. L. McCrory, D. D. Meyerhofer, and C. CherfilsClérouin, Phys. Plasmas 13, 012702 (2006).

${ }^{12}$ S. G. Glendinning, S. N. Dixit, B. A. Hammel, D. H. Kalantar, M. H. Key, J. D. Kilkenny, J. P. Knauer, D. M. Pennington, B. A. Remington, R. J. Wallace, and S. V. Weber, Phys. Rev. Lett. 78, 3318 (1997).
${ }^{13}$ H. Azechi, M. Nakai, K. Shigemori, N. Miyanaga, H. Shiraga, H. Nishimura, M. Honda, R. Ishizaki, J. G. Wouchuk, H. Takabe, K. Nishihara, K. Mima, A. Nishiguchi, and T. Endo, Phys. Plasmas 4, 4079 (1997).

${ }^{14}$ V. A. Smalyuk, S. X. Hu, V. N. Goncharov, D. D. Meyerhofer, T. C. Sangster, D. Shvarts, C. Stoeckl, B. Yaakobi, J. A. Frenje, and R. D. Petrasso, Phys. Rev. Lett. 101, 025002 (2008).

${ }^{15}$ V. A. Smalyuk, S. X. Hu, V. N. Goncharov, D. D. Meyerhofer, T. C. Sangster, C. Stoeckl, and B. Yaakobi, Phys. Plasmas 15, 082703 (2008).

${ }^{16}$ R. Betti, V. N. Goncharov, R. L. McCrory, and C. P. Verdon, Phys. Plasmas 5, 1446 (1998).

${ }^{17}$ Y. C. Lee and P. K. Kaw, Phys. Rev. Lett. 32, 135 (1974).

${ }^{18}$ C. S. Liu and M. N. Rosenbluth, Phys. Fluids 19, 967 (1976).

${ }^{19}$ C. Stoeckl, R. E. Bahr, B. Yaakobi, W. Seka, S. P. Regan, R. S. Craxton, J. A. Delettrez, R. W. Short, J. Myatt, A. V. Maximov, and H. Baldis, Phys. Rev. Lett. 90, 235002 (2003).

${ }^{20}$ S. X. Hu, V. A. Smalyuk, V. N. Goncharov, J. P. Knauer, P. B. Radha, I. V. Igumenshchev, J. A. Marozas, C. Stoeckl, B. Yaakobi, D. Shvarts, T. C. Sangster, P. W. McKenty, D. D. Meyerhofer, S. Skupsky, and R. L. McCrory, Phys. Rev. Lett. 100, 185003 (2008).

${ }^{21}$ T. R. Boehly, D. Munro, P. M. Celliers, R. E. Olson, D. G. Hicks, V. N. Goncharov, G. W. Collins, H. F. Robey, S. X. Hu, J. A. Morozas, T. C. Sangster, O. L. Landen, and D. D. Meyerhofer, Phys. Plasmas 16, 056302 (2009).

${ }^{22}$ P. M. Celliers, D. K. Bradley, G. W. Collins, D. G. Hicks, T. R. Boehly, and W. J. Armstrong, Rev. Sci. Instrum. 75, 4916 (2004).

${ }^{23}$ V. A. Smalyuk, R. Betti, J. A. Delettrez, V. Yu. Glebov, V. N. Goncharov, D. Y. Li, D. D. Meyerhofer, S. P. Regan, S. Roberts, T. C. Sangster, C. Stoeckl, W. Seka, J. A. Frenje, C. K. Li, R. D. Petrasso, and F. H. Séguin, Phys. Plasmas 14, 022702 (2007).

${ }^{24}$ V. A. Smalyuk, D. Shvarts, R. Betti, J. A. Delettrez, D. H. Edgell, V. Yu. Glebov, V. N. Goncharov, R. L. McCrory, D. D. Meyerhofer, P. B. Radha, S. P. Regan, T. C. Sangster, W. Seka, S. Skupsky, C. Stoeckl, B. Yaakobi, J. A. Frenje, C. K. Li, R. D. Petrasso, and F. H. Séguin, Phys. Rev. Lett. 100, 185005 (2008).

${ }^{25}$ J. P. Knauer, P. B. Radha, V. N. Goncharov, I. V. Igumenshchev, R. Betti, R. Epstein, F. J. Marshall, S. P. Regan, V. A. Smalyuk, D. D. Meyerhofer, and S. Skupsky, Bull. Am. Phys. Soc. 52, 233 (2007). 